\title{
Bobbio, a Ciência do Direito e a Função SOCIAL DO JURISTA ${ }^{1}$
}

\section{José Alcebíades de Oliveira Junior"}

Sumário - Introdução; A proposta de ciência jurídica analítica de Norberto BOBBIO; A crítica de Ricardo GUASTINI e algumas observações finais sobre o tema.

\section{INTRODUÇÃO}

Neste texto pretende-se realizar observações à teoria neopositivista da ciência juŕdica de Norberto $B O B B I O$, nas quais se procurará enfatizar especialmente os aspectos diferenciados dessa metodologia em relação às posições clássicas do jusnaturalismo e positivismo, bem como a especificidade com que é tratado o direito enquanto objeto no âmbito dessa corrente, e, por fim, de um modo talvez um pouco audacioso, rediscutir a sintonia ou não daquilo que é proposto como função dos juxistas por essa ciência, em relação ao que se espera como atitude "social" dos juristas em tempos pós-modernos ${ }^{2}$.

1 Versão revista de uma palestra realizada na Faculdade de Filosofra da UFSM, em 31 de agosto de 2004, e que será publicada em urn livro em homenagem a Norberto Bobbio, sobre "Direito, Ética e Política".

Professor Titular de Direito da UFRGS, Pró-Reitor de Extensão da UERGS.

2 Este texto reapresenta alguns aspectos do que escrevemos em "BOBBMO e a filosofia dos juristas", cap.3, POA: Sérgio FABRIS, 1994. Integra, também, o rol de assuntos de uma pesquisa sobre "direitos fundamentais do homem" que aguarda chancela do CNPq, que invariavelmente tem apoiado nossas pesquisas. Por "neopositivismo", entende-se uma das tantas denoninaçōes atribuídas ao "Círculo de Viena" que, nos 1920, sob a orientação, dentre outros, de Rudolf CARNAP e Ludwig WITTGENSTEIN, patrocinou a denominada virada lingüística na filosofia, atribuindo como tarefa essencial dos filósofos, a "arıálise da linguagem da ciència". Por "pós-modernismo", pode-se entender, dentre muitas outras coisas, com LYOTARD, como a presença de um mundo no qual se percebe uma condiçăo de instabilidade dos saberes em geral e da pesquisa cienúfica em particular, em que "o que está ultrapassado não é perguntar-se o que é verdadeiro e o que é justo, e sim considerar-se a ciência como positivista e condenada a este conhecimento jegitimado, a este meio-saber de acordo com os idealistas alemäes". Portanto, a grande meta-questão desse momento, segundo LYOTARD seria: "o que vale o seu "o que vale"?" (LYOTARD, 1986, p. 99 e 100). 
Considerando-se o tema da "cientificidade" da ciência do direito como uma fonte inesgotável de questionamentos, procuraremos, também, nessa nova leitura, demonstrar, primeiro, que o texto "Scienza del diritto e analisi del linguaggio" de BOBBIO (SCARPELLI, 1976 p.287-324; BOBBIO, 1980, p.173-200) representou um efetivo avanço na compreensão daquilo que fazem os juristas; e, em segundo lugar, demonstrar que se o associarmos com as colocações do BOBBIO dos anos 60, especialmente aquelas do seu texto "Ser y Deber Ser em la Ciencia Juridica" (BOBBIO, 1980, p. 201-223), teremos uma ampla, interessante e realista proposta de ciência jurídica, que certamente ainda poderá contribuir en mujto com o processo formativo de juristas teóricos, bem como servir de orientação para atitudes de juristas práticos ${ }^{3}$. Sem prejuízo de uma observação direra da obra de BOBBIO, utilizaremos, também, um texto de Ricardo GUASTINI (1987, p. 119-133), "Los juristas a la busqueda de la ciência - relectura de BOBBIO", em que expõe e critica o BOBBIO dos anos 50 , para justamente tonar possivel a demonstração segundo a qual, $\mathrm{BOBBIO}$, na linha de uma postura espistenológica "tealista", nos anos 60, reviu de modo significativo sua própria obra, pois mesmo sem abandonat a visão analítica ou estrutural, passa a associa-la a uma visão hermenêutica e pragmática de ciência jurídica, ressaltando o aspecto funcional dessa perspectiva de ciência, especialmente no que se refere à discussão em torno da função social dos juristas. Todo esse movimento pode ser sintetizado com a percepção de que se, num primeiro momento, o neopositivismo a partir de várias de suas teses afasta a sociologia do âmbito da ciência do direito, num segundo momento BOBBIO logo percebe a impossibilidade dessa pretensão.

\section{A proposta de ciência jurídica analítica de Norberto BOBBIO}

O texto conferência de BOBBIO antes referido e do qual estamos partindo, introduziu o positivismo lógico (neopositivismo) nos estudos jurídicos em Itália, inscrevendo-se, também, como assinala Ruiz MIGUEL (1983, p.51-52) - um dos maiores comentadores do auror turinês -, em um movimento denominado neoiluminista, tendo representado uma efetiva modificação no pensamento de $\mathrm{BOBBIO}$, e que pode ser traduzida pela passagem de uma filosofia como concep̧̧ão de mundo, para uma filosofia como metodologia, portanto menos especulativa e mais empírica.

3 Cabe salientar aqui, na esteira de um dos mais abalizados intérptetes de BOBBIO no Brasil, Celso LAFER, que uma distinção importante na obra do autor italiano foi a de que existe uma flosofia do direito de flósofos e outra de juristas, e que BOBBIO pratica justamente esta segunda, entendida como uma filosofia geral aplicada ao direito, ou então às questões efetivas dos juristas. Cabe salientar tannbém com LAFER quue dentre os campos de preocupação dos juristas trabalhados por BOBBIO a partir da hegemonia do paradigma positivista-normativista, estão o da validade, o da eficácía e o da justiça do direito enquanto norma positiva, campos esses que trabalhamos em outros momentos, dentre os quais, em "Casos dificeis no pós-positivismo" (OLIVEIRA JUNIOR, 2002, p.203-227; LAFER, $1988, \mathrm{p} .47,48-74)$. 
O trabalho mencionado, em primeiro lugar, assinala a importância de uma atitude prescritiva e crítica aos principais modelos de ciência do direito encontrados na história Racionalismo do Séc. XVII e Positivismo clássico, e que estariam a demonstrar a existência de uma duplicação do saber jurídico, questão que analisaremos adiante. Além disso, denota explicitamente a importância que BOBBIO atribuía a essa altura para uma concepção convencionalista ou nominalista de ciência, própria do positivismo lógico, concepção esta que reunia aspectos das chamadas definições nominais e definições de uso, na busca da eliminação de objetos ideais na ciência, ligados a algum pseudo-conceito de natureza ou de fato social. ${ }^{4}$ Associando tais pressupostos a influência de Hans KELSEN sobre como deveria ser a ciência jurídica, $\mathrm{BOBBIO}$ afirma que os juristas deveriam tomar por objeto de sua ciência as normas jurídicas estatais, mantendo, como objetivo, a necessidade de descrevê-las rigorosamente, visando também purificá-las, integrá-las e ordená-las ná medida do possível.

Para se entender melhor a passagem ao positivismo lógico como padrão epistemológico, convém rever que sobre as concepções fundamentais da ciência jurídica, a Racionalista do $600 \mathrm{e}$ a Positivista do $800, \mathrm{BOBBIO}$ a respeito de ambas trata de demonstrar duas coisas: em primeiro lugar, que propuseram uma concepção da ciência na qual a jurisprudência, querendo permanecer fiel a seu objeto, não podia encontrar nenhum argumento para afirmar sua própria cientificidade; e, em segundo lugar, que ambas deram origem, no campo dos estudos jurídicos, a criação de uma ciência totalmente dissociada da jurisprudência e, portanto, estranha ao trabalho efetivo do jurista. Vislumbrando o Positivismo Lógico como uma terceira concepção, BOBBIO busca com ele uma mudança no entendimento da "razão" e da "verdade" como pontos absolutos de sustentação do saber científco, tal como vinha sendo adotado pelo racionalismo e pelo positivismo clássico (HERNANDEZ GIL, 1987, p.136), substituindo-as por uma concepção puramente instrumental da razão e da verdade. A concepção da verdade absoluta seria substituída por uma concepção convencionalista da verdade. E, por fim, da concepção de uma lógica absoluta passaria a uma concepção que se poderia chamar de phuralista da lógica. ${ }^{5}$

4 Tal concepção implica numa mudança de atitude em relação ì teotia essencialista das palavras e dos termos (ou realismo verbal) elaborada por PLATÃO, e cirada aqui a partir de Hermann KANTOROWICZ, em a "Definición del Derecho", p.33 e 34 (NINO, 1987, p.12).

5 Serta importante destacar o que entende BOBBYO por lógica pluralista. Partindo da razão como tendo um caráter instrumental, e do entendimento de que as proposições primitivas são fruto de convenções, o que implica num rechaço da teoria das essências, BOBBIO não poderia acatat a idéia segundo à qual há por essêneia uma só lógica para as ciências, e sim que, para investigaçôes diversas, correspondem lógicas diversas. Por lógica, BOBBIO entende o conjunto de regtas intelectuais que guiam nossa investigação e a conduzem a um resultado, ou ainda evitarn a falta de um resultado ou põem de manifesto um resultado negativo ou contrário. Mas essa lógica não é a mesma para toda e qualquer ciência (na Matemática e na Física, por exenplo, elas são diferentes), pois senão, ao afirmar os princípios do posiuvismo lógico como adequados ì ciência jurídica, BOBBIO seria obrigado a aceitar a redução do direito a um lógica formal e simbólica, a estilo de CARNAP. Na verdade, BOBBIO reconhece a existência, no âmbito da jurisprudência, de uma lógica material que necessaniamente não coincide (empiricamente) com a lógica formal e simbólica utilizada pạra a descrição dos enunciados proposicionais da ciência, segundo o positivismo lógico em sentido estrito (HERNANDEZ GIL, 1987, p. 137). 
Para uma melhor caracterização da problemática da cientificidade da jurisprudência, observemos os comentários de $\mathrm{BOBBIO}$ sobre as mencionadas concepções racionalista e positivista da ciência jurídica.

Para ilustrar a concepção racionalista de ciência do 600 , parte da afirmação de que ela no fundo se trata de uma expressão da mentalidade iluminista em sentido amplo, contendo, pois, elementos da lógica abstrata e da matenática. Duás asserções a demarcam claramente:

1) o mundo é um sistema ordenado regido por leis universais e necessárias (racionalismo objetivo ou metafisico);

2) o homem é um ser razoável, isto é, dotado de uma faculdade que the permite compreender aquelas leis (racionalismo subjetivo e metodológico).

Nestas duas asserções se funda a concepção da ciência como adequação da razão subjetiva do homem a razão objetiva do universo. A ciência, em definitivo, consiste no descobrimento e formulação de leis que estão já na natureza e que como tais são imutáveis e necessárias; em conseqüência, os resultados que obtém, suas verdades, possuem caráter definitivo (BOBBIO, 1980, p. 175,176).

Diante desses pressupostos, cabe imediatamente a pergunta: qual a relação do objeto da jurisprudência com esses pressupostos de ciência? Certamente muito poucas, haja vista o fato, ressaltado por BOBBIO, sobre as parcas condições da jurisprudência que, na realidade possuiria um objeto bem menos permanente e imutável do que aquele perscrutado pelo racionalismo.

Com efeito, muito embora todas essas distâncias e problemas apontados, inúmeras escolas e doutrinadores do direito enveredaram pelo racionalismo, o que terminou por, paradoxalmente, ao invés de atribuir autoridade à tarefa do jurista, atribuir descrédito, dando origem ao que BOBBIO magistralmente delimitou como sendo uma duplicação do saber jurídico. Como disse, o mundo do conhecimento jurídico foi separado em duas partes: por um lado, criou se um novo saber que, por ser "verdadeiro", não era "iurídico" - o Direito Natural -, e, por outro lado, manteve se o saber tradicional que, por ser "jurídico", não era "verdadeiro"-a Jurisprudência -. (BOBBIO, 1980, p. 177 - 178).

Para ilustrar a concepção positivista de ciência, BOBBIO alude que para um positivista, nem o mundo é um sistema racional nem o homem se encontra de posse de um "órgão" para o conhecimento de uma verdade absolura como a razão. Não existem leis absolutas e pré determinadas, senão que um conjunto de acontecimentos, vale dizer, de fatos. E estes fatos, para entrarem no sistema de ciência, precisam ser controlados experimentalmente. Assim, os fatos constituem para o positivista o pressuposto da análise científica. Mas atenção, somente enquanto puderem ser verificáveis e, assim, mesmo as leis da lógica, que são prévias à experiência, só são tomadas como objeto de análise, na medida em que puderem ser apanhadas como Psicologia, como intenções passiveis de serem avaliadas experimentalmente. Do mesmo modo, a Ética passa a ser avaliada a partir dos comportamentos morais ou dos 
usos e padrōes sociais dominantes que puderem ser avaliados experimentalmente, transformando se, em última análise, em Sociologia.

Diante desses pressupostos, caberia igualmente a pergunta anteriotmente formulada: como se insere a jurisprudência na concepção positivista do saber? A resposta é taxativa: não se insere, em absoluto. Na verdade, a jurisprudência realiza seu trabalho não sobre fatos experimentais, senão que sobre proposições dadas que não são outra coisa do que normas jurídicas, que de modo evidente valem mesmo que não correspondam a fatos. Assim sendo, a jurisprudência também não atende aos padrões de cientificidade do Positivismo.

Devido ao influxo de que para ser ciência a jurispradência deveria basear se em fatos, resultou o surginento da Sociologia e da Psicologia Jurídicas como únicas ciências do direito possiveis, tal como sucedeu na época do racionalismo, quando somente o Direito Natural racionalista seria ciência. Pode se aduzir, neste interim, que talvez advenha desta linha de raciocínio o rechaço permanente tanto às visões idealistas do jusnaturalismo, quanto às visões positivistas de cunho sociológico no âmbito da teoria jurídica. De qualquer modo, emergia daí a mesma problemática da duplicação do saber, onde, de um lado, agregavam se os mentores de uma ciência de fatos, fracionada em Psicologia e Sociologia, e, de outro, aqueles que trabalhavam efervamente com a realidade estatal do direito ou com as nomas jurídicas.

Diantc do exposto, como seria possível, então, pergunta $\mathrm{BOBBIO}$, falar-se em cientificidade da jurisprudência?

Com base no positivismo lógico, demonstra como até agora o contraste entre jurisprudência e ciência foi colocado fundamentalmente a partir da busca de um critério de verdade universal que, no final das contas, intentaria a convergência da jurisprudência com a natureza. Saljentando que o tema da jurisprudência como verdadeira ciência não havia sido ainda colocado com critérios adequados pata uma ciência, ressaltava, dentre outras coisas, que a busca de uma verdade imutável ou a redução do direito a fatos, deveriam ser descartados. Assentado na idéia de que o objeto da ciência do direito são as normas jurídicas, segue entendendo que o ponto a ser abordado deveria ser o de uma rigorosa descrição e delimitação dos conceitos jurídicos envolvidos na prática judiciária, através de um conjunto de proposições lingüísticas que conformariam a ciência jurídica propriamente dita. Com efeito, a ciência se daria na inter-relação de duas linguagens, a do legislador e a do cientista. Este critério, o professor de Turim foi buscar principalmente na obra de CARNAP, um dos fundadores do Círculo de Viena, que fala de uma superação da metafísica por uma análise lógica da linguagem (FARREI, 1979, p.63).

No dizer de BOBBIO (1980, p. 182), as proposições cientificas, segundo os partícipes do positivismo lógico, não são proposições incondicionalmente verdadeiras, no sentido de que reproduzam por intuição (a idéia) ou através de uma operação experimental (o fato), uma verdade, ideal ou de faro, pressuposta; melhor dizendo, são proposições rigorosas, nas quais o acento passa da verdade ao tigor. Como segue BOBBIO, a cientificidade de um 
discurso não consiste na verdade, isto é, na correspondência da enunciação com uma realidade objetiva, senão que no rigor de sua linguagem, vale dizer, na coetência de um enunciado com todos os demais enunciados que formam sistema com aquele (BOBBIO, 1980, P.182-183). Sendo a ciencia dependente de uma linguagem rigorosa ou, noutros termos, sendo ciência somente aquilo que é (ou poderia ser) enunciado rigorosamente do ponto de vista lingǘstico, nosso autor busca definit o que seria uma linguagem rigotosa:

a) quando todas as palavras das proposições primitivas do sistema estão definidas, ou seja, quando estão estabelecidas todas as tegras de seu uso e não são nunca usadas em desrespeito a tais regtas;

b) quando estão estabelecidas as regras em base as quais das proposições primitivas se podem alcançar as proposições derivadas e não se usam outras regras fora das estabelecidas. Ou seja, quando estão perfeitamente dadas as regras de formação das proposições iniciais e as regtas de transformação pelas quais se passa das proposições iniciais as sucessivas. Em conseqüência disso, uma ciênciáa apresenta se como un sistema fechado e coerente.

Para BOBBIO (1980, p.183), entretanto, resta claro que a problemática da ciência jurídica não deve ser reduzida a um fato lingǘstico, muito embora essa dimensão seja fundamental, pois o que se pretende, através de uma ciência jurídica neopositivista, é tonnar intersubjetivo, no mais alto grau, as observações subjetivas existentes entre emissores e receptores. Como são utilizados signos no momento da comunicação jurídica, trata-se de produzir um sentido e uma referência convencionalizada desses signos, o que nos conduz ao entendimento de que não há como deixar de admitir a importância da análise da linguagem para a ciência jurídica.

Assim, tal como foi dito, a linguagem não seria o único aspecto importante para BOBBIO, senão que, como salienta RUIZ MIGUEL (1983, p.57), o historicismo matizaria sua aproximação como empirismo contemporâneo (positivismo lógico), e basicamente em duas direções:

1) como una atitude que mantém uma visão histórica dos problemas, porém de uma maneira diversa de HEGEL e MARX e, natural.

2) como uma metodologia que separa a interpretação social da explicação causal ou

Descendo a detalhes da oscilante adesão às ciências empíricas neopositivistas por parte de BOBBIO (1980, p.184), cabe dizer com ele que mesmo a observação de um experimentador que constitui o começo de uma investigação, e que se formula numa proposição inicial - proposição protocolar - vem expressa numa determinada linguagem. E tal proposição, adquire valor de uma proposição científica, na medida em que puder ser incluída no sistema lingüístico daquela ciência ou possibilite a elaboração de uma nova linguagem científica. Encontra se implicada á́ uma determinada lógica ou discurso, mas que não se trata de uma lógica ou discurso aberto a tudo. Muito embora não sendo uma ciência empírica, a matemática, 
p.ex, possui uma linguagem não só específica como própria, a partir da qual são desenvolvidos os seus axiomas, linguagem esta que terá inevitavelmente de ser respeitada por qualquer tentativa de alteração de seus pressupostos teóricos. ${ }^{6}$

Como exemplo do nascimento de uma proposição protocolat no âmbito da ciência jurídica, pode se dizer que o direito, empiricamente observado, aparece como um conjunto de normas postas por um poder soberano e obedecidas, podendo-se concluir, em termos de proposições, que o direito é uim conjunto de normas de dever ser, e, assim, dar início a um sistema científico. Tais proposições, por vezes são arbitrárias, mas não podem sustentar-se a partir de uma radical contradição com o uso que é feito delas ou em relação aquilo que é verificável naquela primeira proposição. A proposição protocolar, portanto, se insere como pressuposto da ciência neopositivista, e no caso do diteito, ao referir-se ao direito que é e não ao que deveria ser como base do sistema, caracterizou-se por uma proposição primitiva verificável.

Dito isto, cabe a pergunta já anteriormente feita com relação ao racionalismo e o positivismo clássico: o direito se inclui neste novo modo de entender a ciência e, em caso afirmativo, como se inclui?

A resposta de BOBBIO é afimativa e enfática: sim. Além do que o neopositivismo poderia contribuir para o jurista compreender melhor a sua ciência, pois suas teses abrangem de modo mais coetente, o objeto mesmo da ciência jurídica, não o confundindo com o objeto de outras ciências. Uma peculiaridade teórica dessa adesão de BOBBIO é a seguinte: pode se dizer que nuito embora a norma jurídica seja um fato da experiência social, de modo que todos os elementos constitutivos de uma definição geral da regra jurídica são empíricos, a questão da ciência jurídica possui como leito próprio os aspectos lingüísticos desse fenômeno, e, portanto, seu processo de verificação é dependente de uma anterior convenção e não de alguna essencialidade da realidade vivenciada, ao modo do positivismo clássico.

Em reforço ao que está sendo dito, BOBBIO nunca deixou de reconhecer o mérito indiscutivel da teoria normativista de KELSEN e de sua escola na delimitação das regras de comportamento como objeto da jurisprudência. Apesar disto parecer óbvio, com tal assertiva

- Para um melhor esclarecimento do que se entende por proposiçóes protocolares, ver Hernandez. GIL(1987, p. 135 e segs.). Alén disso, conforme Ruiz MIGUISL(1983, p.59), a discussāo em torno a natureza das proposições protocolares ou protocolárias é uma manifestação a mais da eterna disputa entre a epistemologia idealista e a realista. Dentro do empirismo lógico, o ponto de partida de RUSSEL $\mathrm{y}$ WITTGENSTEIN foi realista, defendendo a existência de uma correspondência entre as proposiçóes lingüísticas simples e os fatos atômicos do mundo (atomismo lógico); esta posição foi revisada a principios dos anos trinta por Otto NEURATH a quem seguiria CARNAP num sentido idealista ou convencionalista, considerando que as proposições cientificas primárias não podem comparar se con a realidade extralingǘstica, senão que somente com outras proposiçôes. Com efeito, entendemos que BOBBIO, nos anos 50 , năo consegue superar essa discussão sobre se as normas protocolares sä̀ de natureza empirica ou simplesmente de origem convencional. 
KELSEN eliminou confusões anteriormente patrocinadas pelo racionalismo e pelo positvismo clássico acerca do objeto da jurisprudência (ciência do direito), na medida em que os confundiam com o objeto das regras da lógica e da sociologia. Com efeito, são as regras jurídicas em sua especificidade e não as regras de outra ciência, o objeto da jurisprudência. Ora, uma vez que tais regras são mediadas pela linguagem e a linguagem possui un aspecto social, institucional e se dá com emissores e receptotes situados socialmente, através da análise lingüística seria possível demarcar empiricamente o jurídico do não jurídico de um modo mais preciso.

Porém, os problemas não terminam por aí. Existem as lacunas e as incoerências no sistema jurídico e dai seria de nos perguntarmos imediatamente: qual a real tarefa do jurista, descrever ou prescrever a realidade jurídica a partir das normas postas legalmente? Com qual dessas atitudes - de neutralidade ou engajamento - cumpriria melhor sua função social? Vejamos algumas respostas a essas indagações a seguir.

\section{A crítica de Ricardo GUASTINI e algumas observações finais}

No texto de Ricardo GUASTINI referido ao início no qual interpreta e critica $B O B B I O$, chama a atenção a maneira didática com a qual ressalta o interesse dos juristas por dois modelos de ciência jurídica: o normativismo e o realismo ou comportamentalismo ${ }^{7}$. Para melhor se entender a proposta epistemológica de $\mathrm{BOBBIO}$, tomemos alguns esclarecimentos a respeito de cada un desses modelos, da obra de GUASTINI (1987, p. 119-120):

- para um normativista, a ciência jurídica opera com normas, entendidas como comunicações lingüísticas prescritivas, sobre as quais - ele jurista - elabora proposições descritivas dessas normas;

- para um realista, a ciência jurídica deveria operar com os comportamen tos - enquanto produtores ou guiados por normas -, sobre os quais os juristas expressam ordinárias proposições sobre os fatos que intentam, no mais das vezes, chegar mesmo a prescrever. como eles - os fatos - deveriam ser;

Com efeito, como vimos, a teoria normativista (principalmente a mais influente que é a de matriz kelseniana) propõe uma operação neutra para as relações entre a ciência e a realidade que busca descrever, tendo, por objetivo, "in extremis", aclarar as operaçöes intelectuais que os juristas habitualmente realizam. A teoria realista, por seu turno, ao pretender prescrever como deveria ser a tealidade do direito, termina mesmo por propor aos juristas um modelo de jurisprudência que, necessariamente, não coincide com a realidade cotidiana desses profissionais.

7 Sobre ciência comportamentalista um dos autores mais destacados é Alf ROSS, em suas obras, "Hacia uma ciência realista Del derecho, Critica Del dualismo en el derecho" (1961) e "Cricica Del diritto e analisi del linguaggio"(1982). 
Diante desse quadro, pode-se dizer que o trabalho de $\mathrm{BOBBIO}$ se caracterizou por uma tendência maior pelo normativisno neopositivista. Entretanto, contendo uma tensão muito incômoda que praticamente o leva a um hibridismo entre o empirico e o racional, entre o normativo e a realidade dos fatos, entre descrever e prescrever. $E$ isto pode ser observado tanto na tentariva de aplicação - de una versão que talvez pudesse ser chamada de "impura" do neopositivismo, por defender que a ciência jurídica deveria ser construída com pressupostos concomitantes de verificabilidade e convencionalismo de suas proposições protocolares (PATTARO, 1980, p. 253-257) -, a um objeto de certo modo também impreciso, que poderia ser entendido como aqueles "comportamentos que estão previstos por normas postas", objeto esse que, por seu turno, associa as teses do normativismo puro de KELSEN ao realismo comportamentalista de Alf ROSS (1961). Seguramente, essa leitura só se torna possivel se tomarmos em conta, tal como nos propusemos de início, dois dos principais momentos da epistemologia bobbiana; um, no qual busca rever o positivismo kelseniano a partir do neopositivismo lógico em sua fase analítica, e, outro quando, em 1966, critica e revê sua postura neopositivista anterior, terminando por reconhecer que a ciência juríaica nem descteve nem prescreve a realidade do direito, mas, certamente, a co-constitui, isto é, os juristas colaboram decisivamente com a constituição dessa realidade através dos seus procedimentos intelectuais.

Em busca das confirmações do que estamos dizendo, GUASTINI (1987, p. 121) tomando uma vez mais as reflexões de BOBBIO nos anos 50 , observa que na "Teoria Pura" o direito se con figura como uma espécie de mundo supra-sensivel: o reino do "dever ser", ou seja, um universo năo real regido por leis próprias, formando um sistema fundado em uma norma pressuposta e imaginária, descrita como "norma fundamental". Os enunciados dos juristas não são indicativos, senão que deônticos, o que permite concluir que desde um ponto de vista de sua formulação, eles são indistinguiveis daqueles dos legisladores.

Para BOBBIO, contrariamente, o direito não é mais que um discurso (e neste sentido, um fato): precisamente o discurso prescritivo do legislador. Como já foi dito, as normas são comunicaçôes lingüísticas prescritivas dirigidas a modificar a conduta humana. Assim, a jurisprudência não se constitui em uma enigmática ciência normativa, mas simplesmente em uma possível análise lingüística, uma meta-linguagem sobre uma linguagem objeto (GUASTINI, 1987, p. 121,122).

Por outro lado, BOBBIO esclatece que quando tomamos as normas jurídicas vigentes cono objeto da ciência jurídica, diante delas podemos observar pelo menos dois ângulos: a regra enquanto tal e aquilo que é regulado. No primeiro caso, estaremos diante da ciência formal do direito ou então propriamente dentro da teoria geral do direito, que trataria por excelência das questões estruturais e sistêmicas, e, no segundo caso, diante da dogmática jurídica propriamente dita, enquanto análise do conteúdo mesmo das regras jurídicas ou daquilo que é normatizado. Entretanto, o que GUASTINI $(1987$, p.127, 128) critica no professor italiano é o fato dele não ter feito uma outra distinção que levaria em conta a presença, no âmbito da realidade do direito, de normas propriamente ditas e disposições 
normativas, isto é, de uma diferenciação entre aquilo que as leis ordenam concretamente e aquilo que abstrata e literalmente elas dispõem. Com efeito, o que ele tenta ressaltar e que BOBBlO sabe muito bem, é que Direito e lei não são a mesma coisa e, cono se costuma dizer, as normas enquanto entendidas como as leis postas pelo legislativo, são tão somente os veículos transportadores do direito que termina sendo aplicado, o que torna bastante complicada a posição de descrição neutra do sistema normativo legislado ao mesmo tempo em que se pretende descrever a realidade mesma do mundo do direito, por parte do cientista. Qual o plano que deveria ser privilegiado: o direito legislado ou aquele produzido pelos tribunais?

Por outro lado, quando se trata de aplicar os pressupostos do neopositivismo estudados até aqui às tarefas que os juristas desenvolvem, quais sejam a de purificar, integrar eordenar o sistema juridico, terminamos por nos dar por conta de que por normas entendemse tanto regras explícitas postas pelos legisladores, como também princípios não explícitos, talvez retirados das entranhas do sistema jurídico mesmo ou de outros sistemas, situação que aparece quando existem lacunas de normas ou antinomias de normas. De aí a pergunta que se faz GUASTINI: afinal, segundo BOBBIO a ciência descreve ou transforma a realidade do Direito? Com efeito, com as nuances apontadas, não há como deixar de ver que existem inúmeras dificuldades colocadas para o cientista, e que talvez terminem por retirá-lo de uma postura neutra, gerando uma situação de necessidade de engajamento, situação que BOBBlO não enfrenta nos anos 50. Explicando melhor: quando se trata de descrever normas que foram postas pelo legislador, poderíamos dizer sem muita preocupação que o jurista estaria realizando uma interpretação; entretanto, quando se trata de descrever normas implicitas ou que não foram construídas pelo legislador não se poderia falar já, para além de interpretação, de uma transformação do sistema juridico?(GUASTINI, 1987, p. 127-129).

Por tudo isso é que no ano de 1966, BOBBIO conclui em "Ser e dever ser na ciência juridica", sobre possíveis exageros dos anos 50, quando a epistemologia ao prescrever a descrição como função do cientista, o afastava da realidade dos juristas. Na verdade, como diz BOBBIO (1980), se nos fosse dada a possibilidade de pensar uma meta-jurisprudência adequada àquilo que de fato fazem os juristas, ela não poderia deixar de ser descritiva de uma realidade que tomada em si mesma é prescritiva, qual seja, aquela da atividade dos juristas, situação que aparece de forma incontroversa quando eles se deffrontam com casos de lacunas e antinomias.

Assim, pode-se dizer que no ano de $1966 \mathrm{BOBBIO}$ amplia de modo significativo sua visão da ciência jurídica enquanro interpretação, propondo que para se entender uma lei, se necessário for, deve-se avançar até mesmo sobre as discussões que conduziram a sua confecção no Parlamento, num verdadeiro retorno aos fatos, negando, como que por completo, a anterior separação herdada de KELSEN, entre "ser" e "dever ser".

De qualquer modo, BOBBIO não abandona a interpretação como leito preferencial da ciência jurídica e nem muito menos, em termos gerais, a teoria da ciência jurídica neopositivista, pois nela o que aparece como propriamente objeto do jurista é a interpretação 
da lei. Conforme suas palavras, “... no hay ciencia del derecho, en suma, fuera de la labor del jurista intérprete, el cual precisamente como tal intérprete realiza ese análisis linguístico del que ninguna ciencia puede prescindir y constituye ese lenguaje riguroso en el que consiste según la concepción moderna de la ciencia que ha pasado el problema de la ciencia de la verdad al rigor el caracter esencial de todo estudio que pretenda tener validez de ciencia" (BOBBIO, 1980, p. 187).

Contudo, como assinalou em "Ser e dever ser..."(BOBBIO, 1980, p.211), a tatefá do jurista como intérprete de normas, envolve distintas e complexas etapas, tais como a determinação da norma a ser aplicada que, por seu turno, envolve outras distintas fases do tipo comprovação da existência da norma(sua validade), compreensão para a descoberta do seu significado e, por fim, uma etapa de descobrimento, que seria justamente a busca de normas não explícitas no sistema, e que permitiriam aplicar, de modo atualizado, o sistema em relação aos fatos novos. Por outro lado, a norma nem sempre funciona como um esquema de predição ou que antecipação ao fato que irá ocorrer. Com efeito, muitas das normas jurídicas são de autorização e competências atribuídas a órgãos superiores, cujo comportamento está apenas formalmente determinado pela Constituição, etc...

Pois bem. As discussões e as dificuldades são muitas. Entretanto, não podemos deixar de enfatizar que quanto ao problema da jurisprudência dever ser ou não ser descritiva, por trás dele está a importante questão da função social do jurista tal como assinalamos no próprio título deste trabalho. E sobre esse aspecto, tomemos BOBBIO (1980, p. 219) de modo Literal: "hoje sabemos bem que a tese da ciência jurídica como ciência descritiva nasce em un determinado contexto histórico no qual, para salvaguardar a autoridade de uma fonte privilegiada do direito, se pretende separar radicalmente o momento da reflexão sobre o "ius condirum", que explica mas que não modifica o sistema, das propostas de "ius condendurn", que tendem a modificar o sistema".

Ora, é inegável, nesse momento, a visão de BOBBIO sobre a necessidade de engajamento dos juristas em sua atividade. Contudo, poderiamos partir apressadamente para una conclusão em tons tão somente políticos dos problemas complexos e paradoxats apresentados ao direiro, tais como nos ditos "casos difíceis", paxa utilizar uma expressão de Ronald DWORKIN (2002) $)^{8}$, do tipo interesse do consumidor X interesse do fornecedor; interesse de proteção ambiental $\mathrm{X}$ interesse pelo desenvolvimento; interesse do ser humano X interesse econômico pelo desenvolvimento científico, etc.

Com efeito e acreditando não deturpar o pensamento de BOBBIO, entendemos que em meio a um mundo que mais do que re-afimar certezas navega sob o aumento contínuo dos riscos e das incertezas, os juristas necessitam da substituição dos modelos clássicos que se estabeleceram com base na individualidade humana, na independência disciplinar e nas

\footnotetext{
${ }^{8}$ Sobre o tema ver também "Casos dificeis no pós-positivismo". (OLTVEIRA JUNIOR, 2002, p. 203-227).
} 
certezas epistemológicas, por um modelo que tome em conta a coletividade como um todo, exercite a inter $e$ a transdisciplinariedade e propicie açóes que realizem e transformem o mundo, tornando possivel responder de modo convincente a pergunta de LYOTARD já teferida: "o que vale o seu "o que vale"?"(LYOTARD, 1986, p.100). Em tom ousado e sujeito a críticas, nos perguntaríamos se o que está em jogo hoje, em outras palavtas, não poderia ser o entendimento de que mais valem argumentos com base em realizaçôes efetivas que falam por si do que discussões acadêmicas e por vezes estéteis sobre quais "valores" são mais fundamentais que outros?

A opção por um modelo, ou se se quiset, por uma função engajada e interdisciplinar por parte dos juristas depende, além da capacidade de mostrar-se associada à efetivas condiçôes de realização que cada um possua, de uma certa ousadia e destemor de colocar adiante o já amplo espectro de consciência que hoje temos da complexidade do mundo e da necessidade de determinadas ações no interesse da preservação desse próprio mundo.

Portanto, não há como fazer ciência jurídica fota de uma visão integrada entre o mundo do "ser" e do "dever ser", fora de uma visão associada das posturas normativistas com as posturas sociológica e psicológica. Tal como vem escrevendo a ptofessora Claudia MARQUES (2003, p.71 e segs.), tendo como pano de fundo o professor de HEIDELBERG Erik JAYME (2003), não há como fugir de uma necessário "diálogo das fontes" para a realização plena da ciência jurídica, diálogo esse que deve se dar tanto no âmbito do plano normativo instituído, como também no âmbito de uma relação entre o normativo e a tealidade fática. De maneira singela, lembremos do atualíssimo problema dos "embriões excedentes", que são aqueles que restam posteriormente a uma inseminação artificial nos laboratórios, e que, para alguns setores, já são seres humanos e para outros não. A questão é que para se discutir os diteitos deles; se é que os possuem, necessário se faz uma profunda discussão interdisciplinar sobre o que seja vida, o seu começo, o seu desenvolvimento e o seu fim.

Por derradeiro, a consciência política é fundamental para o cumprimento da função social do jurista, mas não somente ela. É preciso, em rempos pós-modetnos, lançat mão de todos os recursos, intelectuais ou fáticos, ao nosso alcance ou não, para a realização concreta de principios internacionais hoje plenamente intersubjetivados, dentre os quais se sobressai o da defesa da "existência digna" dos seres humanos, presentes e futuros. Segundo nosso ponto de vista, a obrigação social do jurista, entendida no sentido pleno da palavra, deve decorrer principalmente do fato dele - jurista - ter que dar respostas concretas às exigências de um "dever" que se origina da consciência, mas que, sobretudo, responde a exigências outras fruto de um aprofundamento radical das relações do homen com o mundo, como por exemplo na revolução biotecnológica (BOBBIO, 1992, p. 6; FUKUYAMA, 2003), e que só podem ser percebidas a partir de uma "existência transcendental" ou de um "transcendentalismo existencial", se assim nos permitirem os filósofos de falar. Enfim, em meio a complexidade desse mundo pós-moderno, pelo menos chamemos a atenção para o fato de que o viver está a exigir cada vez maiores responsabilidades de todos em suas ações e, pela natureza peculiar da função exercida pelos juristas - dizer o direito -, a eles se aplica esse princípio em grau ainda maior. 


\section{BIBLIOGRAFIA}

BOBBIO, Norberto. La Filosofia di Husserl e la Tendenza Fenomenologica. Rivista di Filosofia, Milano, 1935. pp 47-65.

Scienza del Diritto e Analisi del Linguaggio. In Diritto e Analisi del Linguaggio. Milano. Uberto Scarpelli (org). Comunità, 1976, p.287-324.

-Teoria delia Scienza Giuridica. Torino, Giappichelli, 1950.239 p.

- La Teoria Pura del Diritto ed i suoi Critici. Milano. Rivista trimestrale di Diritto e Procedura Civile, 1954.

. II Positivismo Giuridico. Torino, Editrice Cooperativa Libraria Universitaria, 1986.

. Giusnaturalismo e Positivismo Giuridico. Milano, Edit. Comunita, 1965.

Daila Struttura alla Funzione. Milano, Comunità, 1977.

Diritto e Potere. Saggi su Kelsen. Napoli, Edizioni Scientifiche Italiane, 1992.

BOBBIO, Norberto. Contribución a la Teoria del Derecho. Trad. de Alfonso Ruiz Miguel, Valência, Espanha, Ediç. Artes Gráficás Soles SA, 1980. 404 p.

- El Problema del Positivismo Juridico. Trad, de Ennesto Garzón Valdés, B.A. Argentina, Eudeba, 1965. 114 p.

BOBBIO, Norberto. Revista de Ciências Sociales no.30. Univ. Valparaiso, Chile, 1987.

BOBBIO, Norberto. A Era dos Direitos. Trad. Carlos Nelson Coutinho. RJ:Campus, 1992.

COTTA, Sérgio. Bobbio: un Positivista Inquieto. In I a Teoria Generale del Diritto, Problemi

e Tendenze Attuali. A cura de Uberto Sacarpelli, Milano, Edizioni di Comunità, 1983.

DWORKIN, Ronald. Levando os Direitos a Sério. Tradução Nelşon Boeira et alli. . SP, Martins Fontes, 2002.

FARREL, Martin Diego. La metodologia del positivismo lógico. B.Aires, Abeledo-Perrot, 1979.

FUKUYAMA, Francis. Nosso futuro pós-humano. Conseqüências da tevolução da biotecnologia. RJ: Rocco, 2003

GUASTINI, Ricardo. Los juristas a busqueda de la ciência - relectura de Norberto Bobbio. Revista de Ciências Sociales n.30, Valparaíso, 1987, p.119-133.

HERNANDEZ GIL, Antonio. Bobbio e o Positivismo lógico. In Revista de Ciências Sociales, no, 30, Univ. Valparaíso, 1987, Chile, p.135-148. 
JAYME, Erik. Direito Internacional Privado e Cultura Pós-moderna. In Cadernos do PPGDIR./UFRGS. V. 1,n.1 POA: PPGDIR./UFRGS, 2003, p. 59-68.

LAFER, Celso. A Reconstrução dos Direitos Humanos. Diálogo com o pensamento de Hannah Arendt. SP, Cia. Das Letras, 1988.

LYOTARD, Jean-François. O pós-moderno. Trad. Ricardo Correia Barbosa. 2 ed. RJ: José Olimpio, 1986.

MARQUES, Claudia. Diálogo entre o Código de Defesa do Consumidor e o novo Código Civil; do diálogo das fontes no combate às cláusulas abusivas. In Revista de Direito do Consumidor no. 45. SP: Editora Revista dos Tribunais, 2003.

NINO, Carlos Santiago. Introduccion al analisis del derecho. B.Aires, Abeledo-Pertot: 1987.

OLIVEIRA JUNIOR, José Alcebiades de. Bobbio e a fliosofia dos juristas. POA: Sérgio Fabris, 1994.

OLIVEIRA JUNIOR, José Alcebŕades de. Casos Difíceis no Pós-positivismo. In Hermenêutica Plural. Carlos Boucault e José R. Rodriguez (orgs.). SP: Martins Fontes, 2002 .

PATTARO, Enrico. Fillosofia del Derecho, Derecho y Ciencia Juridica. Trad. de Jose Iturmendi Morales. Madrid, Editorial Reus, 1980.399 p.

ROSS, Alf. Hacia una ciência realista Del derecho. B.Aires: Abeledo-Perrot, 1961.

ROSS, Alf. Critica Del diritto e analisi Del linguaggio. Bologna: Società editrice il Mulino, 1982.

RUIZ MIGUEL, Alfonso. Filosofia y Derecho en Norberto Bobbio. Madrid, Centro de Estudios Constitucionales, 1983.509 p. 